\title{
Trophic functioning with parasites: a new insight for ecosystem analysis
}

\author{
Jesús Ernesto Arias-González ${ }^{1, *}$, Serge Morand ${ }^{2}$ \\ ${ }^{1}$ Laboratorio de Ecología de Ecosistemas de Arrecifes Coralinos, Departamento de Recursos del Mar, \\ Centro de Investigación y de Estudios Avanzados del Instituto Politécnico Nacional, Unidad Mérida, \\ Antigua Carretera a Progreso Km. 73 Cordemex, Mérida, Yucatán 97310, Mexico \\ ${ }^{2}$ Centre de Biologie et de Gestion des Populations (CBGP-IRD), Campus International de Baillarguet, CS 30 016, \\ 34988 Montferrier sur Lez Cédex, France
}

\begin{abstract}
Several balance models of a coral reef ecosystem were created to determine if neglecting parasites significantly alters quantitative or qualitative ecosystem analysis. To better understand how these models react to the addition of parasites: (1) separate and joint analyses of parasitism in fish and benthos compartments were done, (2) it was assumed that parasites have predators or parasites, (3) the quantitative differences in parasites were evaluated and (4) microfauna were introduced into the models. From a quantitative view point the results were mixed; neglecting parasites seemed to cause small changes in conditions in some models. Qualitative differences were quite notable. Inclusion of parasites radically increased the number of pathways in the coral reef ecosystem model (from 362 to 7391), and increased mean trophic efficiency of the system (from 5.2 to $7.7 \%$ ), resulting in a longer food chain (from V to VIII). Evaluation of quantitative differences in parasites showed that the models are very sensitive to parasite biomass, which varied from 0.60 to $0.06 \mathrm{~g} \mathrm{~m}^{-2}$. It is concluded that, even though introduction of parasites may not significantly change total flow of the modelled system, their omission may lead to high inaccuracy in web patterns (i.e. pathways) and trophic structure (i.e. trophic efficiency). Our results are similar to those from other studies of food webs and parasites that used different approaches.
\end{abstract}

KEY WORDS: Food webs · Parasites · ECOPATH with ECOSIM - Aquatic ecosystems · Coral reefs · Trophic efficiency $\cdot$ Ascendancy $\cdot$ Overheads

\section{INTRODUCTION}

Most animal species are infected with parasites, and more than half of all animal species may themselves be parasites at some point in their lives (Marcogliese \& Cone 1997, Poulin \& Morand 2000, 2004). This form of interaction within natural communities may considerably increase food web complexity, because many parasites have complex life cycles, infecting several trophic levels during their lives (Marcogliese \& Cone 1997, Marcogliese 2001, 2002, Parker et al. 2003), and some may form a 'gratis' level, when they themselves host parasites (Polis 1991). This illustrates that parasites are important food web components and that their omission can lead to inaccuracy in predictions of web patterns, trophic structure, connectivity and food chain length (Huxham et al. 1996, Marcogliese \& Cone 1997, Skorping \& Högstedt 2001, Thomas et al. 2005).

Though a number of studies have explored and emphasised the primary role of parasites in food webs (Polis 1991, Freeland \& Boulton 1992, Huxham et al. 1995, Marcogliese \& Cone 1997, Morand \& AriasGonzález 1997, Thompson et al. 2005, Sukhdeo et al. 2005), the role of parasitism in web topology, bioenergetics and functionality has not been thoroughly researched. Theoretical and empirical studies have revealed several structural and functional patterns when parasites are considered in food webs (see 
Marcogliese \& Cone 1997, review). Different theoretical studies have concluded that inclusion of parasites in food webs invalidates the trophic cascade model (Lawton \& Warren 1988), increases model ecosystem feasibility and stability (Freeland \& Boulton 1992), decreases detritus production, and can stabilise or destabilise the system, depending on parasite type (Morand \& Arias-González 1997). Empirical studies incorporating parasites in food webs have shown that, among other implications, introducing parasitism into food webs creates looping, increases maximum and mean chain length, increases the proportion of top predators, decreases the proportion of basal species and determines the position of fish in the food web (Marcogliese \& Cone 1997, review).

Trophic functioning models produce results that allow the description of an ecological system in terms of trophic structure and total system properties (sensu Ulanowicz 1998). Mass balance models and network analysis have been used to study the dynamics and structure of aquatic ecosystems (Ulanowicz 1986, 1997, Wulff et al. 1991, Christensen \& Pauly 1992, 1993a, 1998) and to compare ecosystems of different size and geographic location (Baird \& Ulanowicz 1989, 1993, Baird et al. 1991, Wulff \& Ulanowicz 1991, Monaco \& Ulanowicz 1997). No model, however, has yet introduced a specific parasite compartment, making the present study the first attempt to investigate trophic structure, cycles and ecosystem topology by including parasites within mass balance models.

The principal objective of the present study was to provide some understanding of parasitism in ecosystem analysis by asking questions such as: Does neglecting parasites alter quantitative and qualitative ecosystem analysis to any significant degree? Do ecosystem structure and dynamics change when parasites are introduced into the analysis? It addressed these important issues by creating several balance models of a coral reef ecosystem. To better understand the consequences of parasites in this ecosystem model, the study included: (1) separate and joint evaluation of parasitism in fish and benthos compartments, (2) the assumption that parasites have predators or parasites, (3) evaluation of the quantitative differences in parasites and (4) introduction of microbiota into the models. These analyses were implemented using the ECOPATH with ECOSIM software (Ewe).

\section{MATERIALS AND METHODS}

ECOPATH with ECOSIM (Ewe). Inputs: Ewe computer software combines several approaches for global study of aquatic ecosystems (Arias-González et al. 2004) that were originally developed by Polovina \& Ow
(1983) and Polovina $(1984,1985)$, the network analysis of Ulanowicz (1986), temporal and spatial ecological analyses (Walters et al. 1997). Ewe initially employed assumptions of steady-state systems, but now bases parameters on an assumption of mass balance over a period of time, in this case a year.

Two main equations integrate Ewe. The first describes how the production term for each group or compartment (i) can be split into components (Christensen et al. 2002):

Production $=$ catches + predation mortality + biomass accumulation + net migration + other mortality

or:

$$
B_{i} \times(P / B)_{i} \times E E_{i}-\sum_{j=1}^{N} B_{j} \times(Q / B)_{i} \times D C_{j i}-Y_{i}-E_{i}-B A_{i}=0
$$

where $B_{i}$ is the mean biomass of Functional Group $i_{i}$ $P / B_{i}$, its production/biomass ratio; $E E_{i}$, the ecotrophic efficiency (i.e. the fraction of a prey species' annual production that is consumed by the predator); $Q / B_{i}$, its food consumption per biomass unit; $D C_{j i}$ the fraction of Prey $i$ consumed by Predator $j ; Y_{i}$, the total fishery catch rate of $i_{i} E_{i}$, the net migration rate (emigrationimmigration); and $B A_{i r}$ the biomass accumulation rate for $i$.

This equation includes only the production of $i$, but in a balanced model the energy input and output of all living groups must be balanced. All parameters used to construct an Ewe model need not be entered. Ewe links the production of each group with the consumption of all groups, using these links to estimate missing parameters. Once the missing parameters are estimated, the energy balance is ensured within each group using the equation:

$$
\begin{gathered}
\text { Consumption }=\text { production }+ \text { respiration }+ \\
\text { unassimilated food }
\end{gathered}
$$

For a full review of ECOPATH with ECOSIM, see Christensen et al. (2002).

Outputs: Outputs resulting from analysis inputs are divided into the following 6 segments.

System statistics: Ewe displays a system statistics containing the general calculations of the model (see Table 3). This statistics summary provides a global vision of the behaviour of the model system. Some parameters are considered only if fisheries are introduced into the model. The algorithms for obtaining these value parameters are available on the Ewe web page (Christensen et al. 2002).

Trophic structure: The trophic structure analysis describes the successive trophic levels, the importance of detritivory versus herbivory and the Lindeman trophic aggregation (Kay et al. 1989). Each consumer has several consumption pathways; when results are weighted by the trophic level value and summed, they 
produce the effective trophic level (Ulanowicz 1999). For example, if a species or compartment receives $15 \mathrm{U}$ of flow along a pathway of Length 2 and $5 \mathrm{U}$ along a pathway of Length 3 , then it is acting $75 \%$ as a herbivore (trophic level $=2$ ) and $25 \%$ as a carnivore (level $=$ $3)$. The effective trophic position becomes $(0.75 \times 2)+$ $(0.25 \times 3)=1.75$. Primary producers and all abiotic activity are considered to have a trophic position of 1 , while herbivores or detritivores have a position of 2 . The consumption pathways can also be distributed into trophic level categories, corresponding to integers, according to their different feeding pathways. This is the basis of the Lindeman spine or trophic aggregation, which summarises the total network in a single linear chain (Kay et al. 1989). The efficiency of the transfer from one trophic level to the next is the ratio of the input into a trophic level to the amount that that level passes onto the next level (Ulanowicz 1999). The contribution of each trophic level to respiration, imports and exports is also evaluated.

Cycling and pathways: Ewe includes a number of routines for this purpose: the Finn cycling index is the proportion of total system activity $T$ (see below) devoted to material and energy recycling (Finn 1976), and gives an idea of how retentive a system is. Average path length measures the average number of transfers that a flux unit will experience from its entry into the system until leaving the system (Finn 1976). Ewe also introduces a modified predatory cycling index, computed after cycles involving detritus have been removed.

Mixed impacts: Ulanowicz \& Puccia (1990) developed a method to assess the direct and indirect impacts of the different compartments. A routine based on their method has been implemented in Ewe (Christensen et al. 2002. The mixed trophic impacts can be used as a form of sensitivity analysis, because they can indicate if the effect of one group on another is negligible, or not. According to Christensen et al. (2002) one should regard the impact routine as a tool for indicating the possible impact of indirect or direct interactions, not as an instrument for predictions.

Global system attributes: This output segment provides values for global system attributes as defined by Ulanowicz (1986) and Ulanowicz \& Norden (1990). Ascendancy $(A)$, in the form suggested by Ulanowicz \& Norden (1990), measures flow size and organisation, and is a product of the size and a measure of flow coherence or the inherent information of the flows, called the average mutual information of the flow structure. Total system throughput $(T)$ addresses the total amount of flows (consumption, exports, respiratory flows and flow into detritus), including inputs and outputs. Total throughput, which serves as a measure of system size, multiplied by the entropy of the individ- ual flows, yields development capacity $(C)$, the upper boundary of ascendancy (Ulanowicz 1999). Development capacity defines the maximum development of the system. According to Ulanowicz \& Norden (1990), ascendancy appears to grow toward its theoretical limit, $C$, but is destined to fall short of that limit by a non-negative amount, $C-A$, which is defined by system overhead. Overheads can be segregated in terms generated by dissipations (respirations), inputs, exports and redundancy (internal flow), where redundancy is the residual uncertainty associated with the occurrence of parallel paths.

Model compartments: Of the different mass balance models developed by Arias-González (1993) for fringing and barrier reefs off Moorea Island (French Polynesia), the Moorea Barrier Reef Model (MBRM) was employed for the present study. The original parameters and flux of these models were derived from ECOPATH II (Christensen \& Pauly 1992).

The original 45 compartments in the MBRM were adjusted for this study into 15 (without parasites), 16 (with parasites), 16 (without parasites, with microfauna) and 17 (with parasites, and microfauna) compartment models. The grouping of compartments was done using the aggregation routine of Ewe, adding similar species groups in more general trophic guilds. Compartment aggregation was based on compartments having approximately the same overall trophic position, production to biomass ratios $(P / B$ ratios) and diet (Christensen \& Pauly 1992, Monaco \& Ulanowicz 1997). Aggregation produced a total of 7 fish trophic compartments, including piscivorous, carnivorous, browsers, omnivorous, herbivorous, planktonophagous and fish larvae; 3 heterotrophic benthos compartments for the model without microfauna (macrofauna, meiofauna and corals); 4 heterotrophic benthos compartments for the model with microfauna (macrofauna, meiofauna, microfauna and corals); 1 heterotrophic and autotrophic plankton compartment; 1 autotrophic benthos compartment; and the detritus compartment. For the purposes of this study, a parasite compartment was added to all the original mass balance models (Table 1).

Several models without (wo/) and with (w/) parasites and microfauna were constructed to relate trophic functioning to parasite and microbe influences: (1) wo/parasites, (2) w/parasites in benthos and parasites, (3) w/parasites in fish and parasites, (4) w/parasites in all the heterotrophic compartments, (5) w/ microfauna and wo/parasites and (6) w/microfauna and w/parasites in all heterotrophic compartments. All these models were tested using only the MBRM.

Parameterisation. Ewe initial parameters (biomass, $P / B, Q / B, E E$ and diet) for fish, benthos, microfauna and plankton compartments were obtained directly 
from the models of Arias-González (1993) and AriasGonzález et al. (1997). Because no information was available on the biomass, mortality and consumption rates for parasites, different assumptions were established for the present study. Initial biomass was considered to oscillate between 0.1 and $0.2 \%$ of host biomass, so total biomass was obtained from the average value of heterotrophic compartment biomasses. Parasite $Q / B$ and $P / B$ ratios were estimated to range within the $P / B$ and $Q / B$ values of minor macrofauna (i.e. isopods, copepods, annelids), meiofauna (i.e. copepods, nema- todes) and microfauna (i.e. bacteria), considering that some parasite sizes fall within the size range of these groups. Parasite diet was assumed to be proportional to heterotrophic compartment biomass. Predation on parasites was placed at the minimum possible proportion $(0.001 \%)$ that can be introduced into the program, and was equal for all heterotrophic compartments. The preliminary data were introduced into the 'Ecoranger' routine of Ewe to valorise model uncertainty and estimate the parasite biomass production that the system model could support, producing a range of $10 \%$ of the

Table 1. Output parameters for the coral reef ecosystem scenarios without (Wo/P) and with parasites and microfauna (W/P-BFP, in heterotrophic benthos, fish and parasites) $(P / B$ : production/biomass; $Q / B$ : consumption/biomass; EE: ecotrophic efficiency; TL: trophic level). Biomass units in tonnes wet weight $\mathrm{km}^{-2}$

\begin{tabular}{|c|c|c|c|c|c|c|}
\hline \multirow[t]{2}{*}{ Group designation and name } & \multirow[t]{2}{*}{$\mathrm{TL}$} & \multicolumn{2}{|c|}{ Biomass } & \multirow[t]{2}{*}{$P / B\left(\mathrm{yr}^{-1}\right)$} & \multirow[t]{2}{*}{$Q / B\left(\mathrm{yr}^{-1}\right)$} & \multirow[t]{2}{*}{ EE } \\
\hline & & $\mathrm{Wo} / \mathrm{P}$ & W/P-BFP & & & \\
\hline 1. Piscivorous fish & 3.3 & 35.4 & 35.5 & 0.36 & 8.12 & 0.513 \\
\hline 2. Carnivorous fish & 3.0 & 46.6 & 60.1 & 1.60 & 12.76 & 0.891 \\
\hline 3. Grazer fish & 2.6 & 9.2 & 10.2 & 2.56 & 17.14 & 0.946 \\
\hline 4. Omnivorous fish & 2.3 & 4.4 & 4.7 & 2.88 & 24.00 & 0.953 \\
\hline 5. Herbivorous fish & 2.0 & 147 & 147 & 1.84 & 34.00 & 0.740 \\
\hline 6. Zooplanktivorous fish & 3.1 & 0.5 & 0.5 & 3.91 & 19.00 & 0.979 \\
\hline 7. Fish larvae & 3.1 & 0.2 & 0.2 & 137.28 & 653.71 & 0.659 \\
\hline 8. Macrofauna & 2.2 & 210 & 256 & 4.37 & 29.45 & 0.780 \\
\hline 9. Meiofauna & 2.5 & 46.8 & 46.8 & 31.00 & 184.00 & 0.689 \\
\hline 10. Corals & 1.5 & 45.4 & 45.4 & 13.35 & 27.82 & 0.380 \\
\hline 11. Zooplankton & 2.3 & 1.7 & 3.5 & 61.63 & 278.00 & 0.836 \\
\hline 12. Microfauna & 2.0 & 30.4 & 30.4 & 282.20 & 1.808 .97 & 0.507 \\
\hline 13. Parasites & 3.3 & - & 0.6 & 21.60 & 109.82 & 0.690 \\
\hline 14. Autotrophic benthos & 1.0 & 1843 & 1843 & 10.65 & - & 0.364 \\
\hline 15. Phytoplankton & 1.0 & 0.3 & 0.3 & 552.86 & - & 0.862 \\
\hline 16. Detritus & 1.0 & 655 & 655 & - & - & 0.985 \\
\hline
\end{tabular}

Table 2. Diet composition matrix for the coral reef ecosystem with parasite and microfauna scenarios. Diet composition for other trophic groups different to parasites have the same item proportions as in the model without parasites

\begin{tabular}{|c|c|c|c|c|c|c|c|c|c|c|c|c|c|}
\hline \multirow[t]{2}{*}{ Prey } & \multicolumn{13}{|c|}{ Predator } \\
\hline & 1 & 2 & 3 & 4 & 5 & 6 & 7 & 8 & 9 & 10 & 11 & 12 & 13 \\
\hline 1. Piscivorous fish & 0.007 & & & & & & & & & & & & 0.065 \\
\hline 2. Carnivorous fish & 0.233 & 0.017 & & & & & & & & & & & 0.085 \\
\hline 3. Grazer fish & 0.072 & 0.004 & & & & & & & & & & & 0.017 \\
\hline 4. Omnivorous fish & 0.042 & & & & & & & & & & & & 0.008 \\
\hline 5. Herbivorous fish & 0.526 & 0.040 & & & & & & & & & & & 0.268 \\
\hline 6. Zooplanktivorous fish & 0.006 & & & & & & & & & & & & 0.001 \\
\hline 7. Fish larvae & & 0.006 & & & & 0.010 & & & & & 0.100 & & \\
\hline 8. Macrofauna & 0.112 & 0.731 & 0.171 & 0.159 & & 0.150 & 0.027 & & & & & & 0.384 \\
\hline 9. Meiofauna & & 0.002 & 0.004 & 0.001 & & & 0.029 & 0.090 & & & & & 0.085 \\
\hline 10. Corals & & 0.060 & 0.663 & 0.046 & & & 0.008 & & & & & & 0.083 \\
\hline 11. Zooplankton & & 0.027 & 0.002 & 0.040 & & 0.654 & 0.001 & & 0.013 & 0.030 & 0.699 & & 0.003 \\
\hline 12. Microfauna & & 0.002 & & 0.010 & & & 0.116 & 0.370 & 0.030 & 0.260 & & & \\
\hline 13. Parasites & 0.001 & 0.001 & 0.001 & 0.001 & & 0.001 & 0.001 & & & & 0.001 & & 0.001 \\
\hline 14. Autotrophic benthos & & 0.009 & 0.100 & 0.740 & 0.990 & 0.135 & 0.224 & & 0.313 & & & & \\
\hline 15. Phytoplankton & & & & & & & 0.009 & & & 0.080 & & & \\
\hline 16. Detritus & & 0.101 & 0.059 & 0.003 & 0.010 & 0.050 & 0.585 & 0.540 & 0.643 & 0.630 & 0.200 & 1 & \\
\hline Sum & 1 & 1 & 1 & 1 & 1 & 1 & 1 & 1 & 1 & 1 & 1 & 1 & 1 \\
\hline
\end{tabular}


variation coefficient. Random input variables were drawn from normal distributions for each basic parameter. The process was repeated to generate a theoretical frequency distribution for each parameter using Monte Carlo simulations. A total of 100000 models were run, and the best-fitting model of these was used for further analysis. The biomass, $P / B, Q / B$ outputs and diet inputs are given in Tables $1 \& 2$.
The Lindeman chain in the coral reef models with parasites consisted of Trophic Levels VII (parasites in benthos-parasites), IX (parasites in fish-parasites) and VIII (parasites in all heterotrophic compartments without and with microfauna), while the coral reef model without parasites was formed of VII (without and with microbiota) levels (Table 5). Piscivorous and carnivorous fish and parasite flows reached the

\section{RESULTS}

\section{System statistics}

Total activity, measured by total system throughput (total consumption, exports, respiration and flow into detritus, in this case, in t wet weight $\mathrm{km}^{-2} \mathrm{yr}^{-1}$ ) was higher in all the systems with parasites (SWP) than in the system without parasites (SWOP) (Table 3). There was an increase in all summary attributes: total production and biomass ( $\mathrm{t}$ wet weight $\mathrm{km}^{-2}$ ), excluding detritus; estimated net primary production; connectivity index; and omnivory. Comparison of the models with parasites showed that total activity increased slightly as a function of the interaction of the parasites with the heterotrophic compartments. Despite the fact that the total activity value responded in this way, the values that form this attribute did not. The sum of all exports and flows into detritus decreased relatively as parasites were integrated with predators in the benthos-parasites, fish-parasites and all heterotrophic compartment models. The opposite was true for the sum of all consumption and respiratory flows, the values for which increased.

\section{Trophic structure}

Mean trophic levels did not vary within similar compartments of all models, with or without microbiota. Parasites exhibited a second trophic level when they occurred in benthos and all heterotrophic compartments. When introduced into the fish compartment, they had the highest trophic level, even higher than piscivorous fish (Fig. 1, Table 4). The total and per compartment number of pathways varied enormously between SWOP and SWP models (Fig. 1). Total number of paths varied from 181 in the SWOP models to 7995 in the SWP models. Variation in number of pathways was of the same degree per compartment, between models.

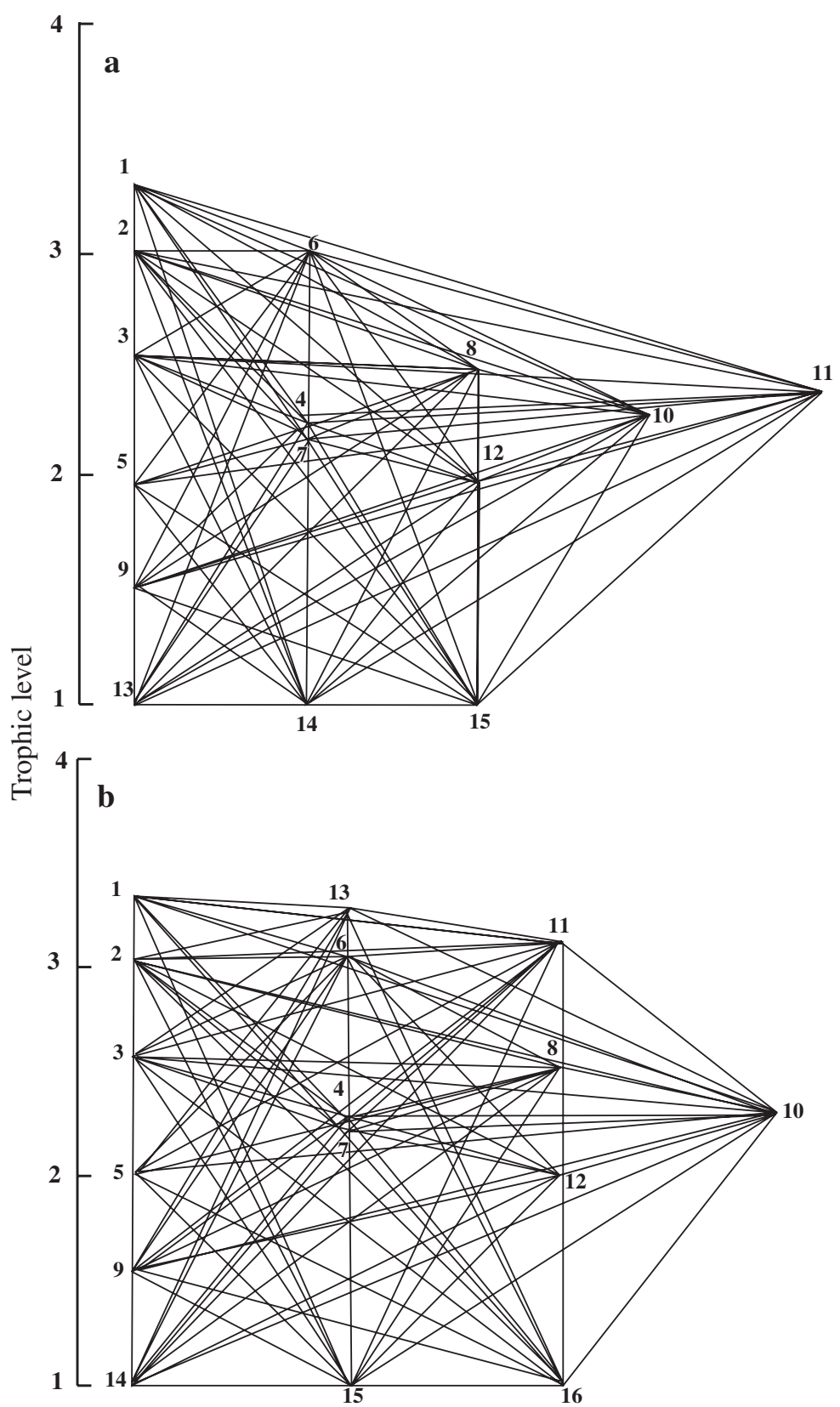

Fig. 1. Food web scheme for the coral reef system (a) without parasites: and (b) with parasites. 1: piscivorous fish; 2: carnivorous fish; 3: grazer fish; 4: omnivorous fish; 5: herbivorous fish; 6: zooplanktivorous fish; 7: fish larvae; 8: macrofauna; 9: meiofauna; 10: corals; 11: zooplankton; 12: microfauna; 13: parasites; 14: autotrophic benthos; 15: phytoplankton; 16 : detritus 
upper trophic levels, though their overall values were small from levels VI to IX. Compartments with low mean trophic levels (i.e. herbivorous fish, macrofauna, meiofauna, zooplankton, etc.) were assigned mainly to the Trophic Level II in the Lindeman chain, meaning they were feeding mainly on autotrophic compartments and detritus. Trophic Level III showed very high carnivory activity, which decreased drastically in the following trophic levels. Parasite and piscivorous fish activity occurred mainly in Trophic Level III, though they were also important in Trophic Level IV. On average, the transfer efficiencies of the coral reef models with parasites were higher (from 5.4 to $7.4 \%$ ) than for the model without parasites $(5.2$

Table 3. Summary of results for systems without (Wo) and with (W) parasites, including respective units (Wo/P: without parasites; W/P-BP: with parasites in heterotrophic benthos and parasites; W/P-FP: with parasites in fish and parasites; W/P-BFP: with parasites in heterotrophic benthos, fish and parasites; Wo/P-M: without parasites, with microfauna; W/P-M-BFP: with parasites in heterotrophic benthos, fish and parasites, with microfauna)

\begin{tabular}{|c|c|c|c|c|c|c|c|}
\hline Parameter & Wo/P & W/P-BP & W/P-FP & W/P-BFP & Wo/P-M & W/P-M-BFP & Units \\
\hline Sum of all consumption & 23731.56 & 24830.76 & 24912.02 & 24968.38 & 78837.09 & 79917.73 & Wet wt $\left(\mathrm{t} \mathrm{km}^{-2} \mathrm{yr}^{-1}\right)$ \\
\hline Sum of all exports & 4598.96 & 5410.54 & 5354.67 & 5319.53 & 1206.43 & 1007.77 & Wet wt $\left(\mathrm{t} \mathrm{km}^{-2} \mathrm{yr}^{-1}\right)$ \\
\hline Sum of all respiratory flows & 9529.72 & 9947.19 & 9995.69 & 10030.82 & 19057.51 & 19208.04 & Wet wt $\left(\mathrm{t} \mathrm{km}^{-2} \mathrm{yr}^{-1}\right)$ \\
\hline Sum of all flows into detritus & 17194.54 & 18467.17 & 18409.46 & 18374.33 & 66420.33 & 66646.16 & Wet wt $\left(\mathrm{t} \mathrm{km}^{-2} \mathrm{yr}^{-1}\right)$ \\
\hline Total system throughput & 55055.00 & 58656.00 & 58672.00 & 58693.00 & 165521.00 & 166780.00 & Wet wt $\left(\mathrm{t} \mathrm{km}^{-2} \mathrm{yr}^{-1}\right)$ \\
\hline Sum of all production & 17342.00 & 18740.00 & 18743.00 & 18753.00 & 31938.00 & 32217.00 & Wet wt $\left(\mathrm{t} \mathrm{km}^{-2} \mathrm{yr}^{-1}\right)$ \\
\hline Mean trophic level of the catch & - & - & - & - & - & - & \\
\hline $\begin{array}{l}\text { Gross efficiency (catch/net primary } \\
\text { production) }\end{array}$ & - & - & - & - & - & - & \\
\hline \multicolumn{8}{|l|}{ Input total net primary production } \\
\hline $\begin{array}{l}\text { Calculated total net primary } \\
\text { production }\end{array}$ & 13999.87 & 15221.64 & 15216.49 & 15216.49 & 20090.21 & 20089.53 & Wet wt $\left(\mathrm{t} \mathrm{km}^{-2} \mathrm{yr}^{-1}\right)$ \\
\hline \multicolumn{8}{|l|}{ Unaccounted primary production } \\
\hline $\begin{array}{l}\text { Total primary production/total } \\
\text { respiration }\end{array}$ & 1.47 & 1.53 & 1.52 & 1.52 & 1.14 & 1.05 & \\
\hline Net system production & 4470.15 & 5274.54 & 5220.8 & 5185.67 & 1032.71 & 881.49 & Wet wt $\left(\mathrm{t} \mathrm{km}^{-2} \mathrm{yr}^{-1}\right)$ \\
\hline $\begin{array}{l}\text { Total primary production/total } \\
\text { biomass }\end{array}$ & 7.99 & 7.98 & 7.96 & 7.96 & 8.31 & 8.09 & \\
\hline Total biomass/total throughput & 0.03 & 0.03 & 0.03 & 0.03 & 0.02 & 0.02 & \\
\hline Total biomass (excluding detritus) & 1750.36 & 1908.21 & 1911.89 & 1912.12 & 2421.11 & 2484.08 & Wet wt $\left(\mathrm{t} \mathrm{km}^{-2}\right)$ \\
\hline Total catches & - & - & - & - & - & - & Wet wt $\left(\mathrm{t} \mathrm{km}^{-2} \mathrm{yr}^{-1}\right)$ \\
\hline Connectance index & 0.31 & 0.33 & 0.35 & 0.37 & 0.33 & 0.37 & \\
\hline \multicolumn{8}{|l|}{ Cycling } \\
\hline System omnivory index & 0.09 & 0.09 & 0.11 & 0.11 & 0.15 & 0.15 & \\
\hline Throughput cycled (excluding detritus) & 1007.08 & 1044.29 & 1041.66 & 1044.45 & 997.47 & 1042.75 & Wet wt $\left(\mathrm{t} \mathrm{km}^{-2} \mathrm{yr}^{-1}\right)$ \\
\hline Predatory cycling index & 4.87 & 4.81 & 4.77 & 4.76 & 3.05 & 3.11 & $\begin{array}{c}\text { Throughput w/o } \\
\text { detritus (\%) }\end{array}$ \\
\hline Throughput cycled (including detritus) & 8.07 & 8.19 & 8.18 & 8.22 & 1.06 & 1.11 & Wet wt $\left(\mathrm{km}^{-2} \mathrm{yr}^{-1}\right)$ \\
\hline Finn's cycling index & 22.65 & 21.73 & 21.7 & 21.64 & 56.63 & 56.5 & Total throughput (\%) \\
\hline Finn's mean path length & 3.91 & 3.82 & 3.82 & 3.82 & 8.17 & 8.25 & \\
\hline Finn's straight-through path length & 2.06 & 2.08 & 2.08 & 2.08 & 1.66 & 1.69 & Without detritus \\
\hline Finn's straight-through path length & 3.01 & 2.99 & 2.99 & 3.01 & 3.54 & 3.59 & With detritus \\
\hline \multicolumn{8}{|l|}{ Ascendancy } \\
\hline Import & 0 & 0 & 0 & 0 & 0 & 0 & Flowbits \\
\hline Internal flow & 44410.3 & 46250.9 & 46436.3 & 46422.5 & 149445.3 & 151243.0 & Flowbits \\
\hline Export & 7721.3 & 9021.0 & 8954.2 & 8912.9 & 1589.2 & 1333.6 & Flowbits \\
\hline Respiration & 12021.8 & 12814.3 & 12836.2 & 12856.4 & 23293.9 & 23048.4 & Flowbits \\
\hline \multicolumn{8}{|l|}{ Overheads } \\
\hline Import & 0 & 0 & 0 & 0 & 0 & 0 & Flowbits \\
\hline Internal flow & 125122.2 & 134927.6 & 135195.5 & 135921.9 & 288963.7 & 298362.0 & Flowbits \\
\hline Export & 8749.8 & 9582.7 & 9539.8 & 9513.0 & 6976.5 & 6094.3 & Flowbits \\
\hline Respiration & 35178.4 & 37082.8 & 37352.5 & 37644.9 & 78447.8 & 80160.6 & Flowbits \\
\hline \multicolumn{8}{|l|}{ Capacity } \\
\hline Import & 0 & 0 & 0 & 0 & 0 & 0 & Flowbits \\
\hline Internal flow & 169532.6 & 181178.5 & 181631.9 & 182344.4 & 438409.1 & 449605.0 & Flowbits \\
\hline Export & 16471.1 & 18603.7 & 18493.9 & 18425.9 & 8565.8 & 7427.9 & Flowbits \\
\hline Respiration & 47200.2 & 49897.1 & 50188.7 & 50501.3 & 101741.6 & 103208.9 & Flowbits \\
\hline
\end{tabular}


to $7.0 \%$ ) (Table 5). Transfer efficiencies in the coral reef models with parasites in fish-parasites and all heterotrophic compartments were very similar from Trophic Level II to VIII. In the model without parasites and in the model with parasites in benthosparasites, the transfer efficiencies decreased sharply from Trophic Level IV to V. Biomass by trophic level was relatively higher in the coral reef models with parasites than in those without parasites.

\section{Cycling and pathway length}

The results for cycling and pathways were mixed (Table 3). The amount of throughput cycled, excluding and including detritus, was relatively higher in the SWP than in the SWOP coral reef models. In the microbiota example, the cycling index and average pathway lengths were relatively higher in the model with parasites. In the parasite models without microbiota, in contrast, the predatory cycling index and average mean pathway length were smaller than in the model without parasites. The Finn's cycling index was highest in the models without parasites.

\section{Mixed impacts}

The predation of parasites in the benthos-parasite compartment did not have a global effect on the interaction of the SWP model when compared to the SWOP model (Fig. 2). Parasites had a slight indirect negative effect on piscivorous and zooplanktivorous fish. They had a substantial effect, however, on carnivorous fish, likely due to a direct negative response of the parasites' effect on macrofauna and the very same parasites. All other compartments had a positive response to the parasite-benthos-parasite interaction, especially herbivorous fish, microfauna and corals. This interaction also had a positive effect on detritus.

When parasites were induced to prey in the fish-parasite compartments, the structure of the global system interaction changed significantly. There was not only an increase in the negative effects on the system, but an increase in magnitude. The parasites produced a strong negative effect on piscivorous fish and, to a lesser extent, on macrofauna, corals and autotrophic benthos. In all other compartments this interaction produced a positive impact, including on the parasites themselves. This interaction also had a positive impact on detritus, but to a lesser degree than in the parasite-benthos-parasite interaction.

When parasites were induced to prey in all heterotrophic compartments, the general impact scheme did not vary much in relation to the previous interaction, and some of the impacts directly produced by the parasites were very similar. There was a slight decrease in the negative impact on piscivorous fish and fish larvae, as well as in the positive impact on zooplanktivorous and omnivorous fish.

Similar to the way they behaved in the models without microfauna, when the parasites were induced to prey on all heterotrophic compartments in the model with microfauna, the mixed impact routine illustrated the importance of parasites. Parasites had an important negative impact in piscivorous fish, macrofauna, corals and autotrophic benthos, but a positive impact in all other groups.

Table 4. Number of pathways (NP) and trophic levels (TL) for the different compartments and models as defined in Table 3

\begin{tabular}{|c|c|c|c|c|c|c|c|c|c|c|c|c|}
\hline \multirow{2}{*}{ Compartment } & \multicolumn{2}{|c|}{ Wo/P } & \multicolumn{2}{|c|}{ W/P-BP } & \multicolumn{2}{|c|}{ W/P-FP } & \multicolumn{2}{|c|}{ W/P-BFP } & \multicolumn{2}{|c|}{ Wo/P-M } & \multicolumn{2}{|c|}{ W/P-M-BFP } \\
\hline & NP & $\mathrm{TL}$ & NP & TL & NP & TL & NP & TL & NP & TL & NP & TL \\
\hline 1. Piscivorous fish & 87 & 3.29 & 207 & 3.29 & 716 & 3.29 & 850 & 3.29 & 214 & 3.33 & 2242 & 3.34 \\
\hline 2. Carnivorous fish & 34 & 2.93 & 78 & 2.93 & 372 & 2.93 & 421 & 2.93 & 214 & 3.04 & 2178 & 3.05 \\
\hline 3. Grazer fish & 15 & 2.52 & 31 & 2.52 & 175 & 2.52 & 193 & 2.52 & 28 & 2.56 & 605 & 2.56 \\
\hline 4.Omnivorous fish & 15 & 2.24 & 31 & 2.24 & 219 & 2.24 & 237 & 2.24 & 29 & 2.28 & 596 & 2.28 \\
\hline 5. Herbivorous fish & 2 & 2.00 & 2 & 2.00 & 2 & 2.00 & 2 & 2.00 & 2 & 2.00 & 2 & 2.00 \\
\hline 6. Zooplanktivorous fish & 13 & 2.85 & 41 & 2.86 & 361 & 2.86 & 392 & 2.86 & 24 & 3.04 & 1050 & 3.05 \\
\hline 7. Fish larvae & 2 & 2.91 & 14 & 2.88 & 160 & 2.88 & 173 & 2.88 & 4 & 2.4 & 513 & 3.12 \\
\hline 8. Macrofauna & 8 & 2.07 & 12 & 2.07 & 88 & 2.07 & 93 & 2.07 & 15 & 2.20 & 256 & 2.20 \\
\hline 9. Meiofauna & 1 & 2.10 & 1 & 2.10 & 1 & 2.10 & 1 & 2.10 & 2 & 2.51 & 2 & 2.51 \\
\hline 10. Corals & 3 & 1.50 & 3 & 1.49 & 3 & 1.49 & 3 & 1.49 & 6 & 1.52 & 6 & 1.52 \\
\hline 11. Zooplankton & 1 & 2.03 & 1 & 2.03 & 1 & 2.03 & 1 & 2.03 & 3 & 2.3 & 3 & 2.30 \\
\hline 12. Microfauna & - & - & - & - & - & - & - & - & 1 & 2.00 & 1 & 2.00 \\
\hline 13. Parasites & - & - & 12 & 3.05 & 168 & 3.41 & 181 & 3.17 & - & - & 541 & 3.27 \\
\hline 14. Autotrophic benthos & 0 & 1.00 & 0 & 1.00 & 0 & 1.00 & 0 & 1.00 & 0 & 1.00 & 0 & 1.00 \\
\hline 15. Phytoplankton & 0 & 1.00 & 0 & 1.00 & 0 & 1.00 & 0 & 1.00 & 0 & 1.00 & 0 & 1.00 \\
\hline Total & 181 & - & 433 & & 2266 & & 2547 & & 542 & & 7995 & - \\
\hline
\end{tabular}


Table 5. Transfer efficiency (TE, \%) and biomass ( $t$ wet weight $\mathrm{km}^{-2}$ ) of each trophic compartment for each system model as defined in Table 3

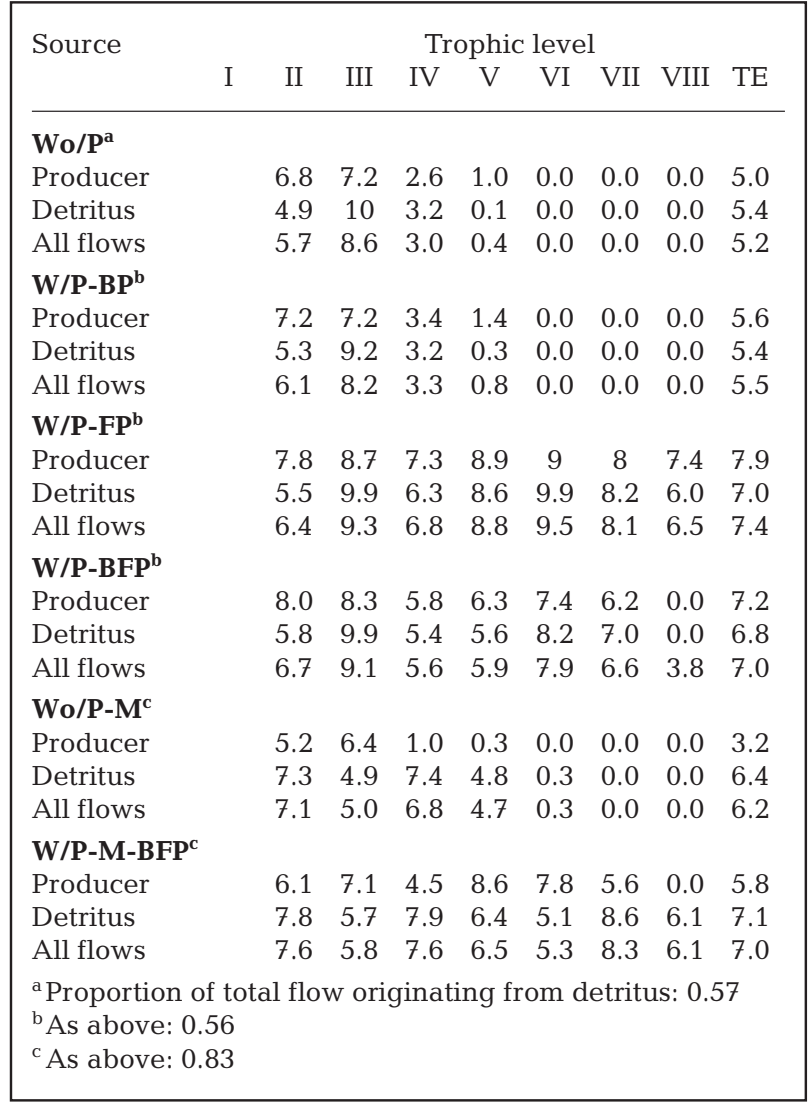

\section{Global network attributes}

The development capacity of the SWP coral reef models was higher than that of the SWOP model and, consequently, so were their ascendancy and overheads (Table 3).

\section{DISCUSSION}

The most remarkable general change in the food web structure of the modelled systems was in the interaction between compartments and not in the absolute flows. The interaction of parasites with heterotrophic benthos, plankton and fish produced an extraordinary number of pathways, increased chain length and omnivory index and increased the efficiency of the model system, making the highest compartments more important. The average and direct pathway length, quantity of recycled mass flow and relative ascendancy and overhead, in contrast, did not change when parasites were included in the model systems.
Total activity and mass production were also very similar between models, though there was a slight increase in these parameters in the system with parasites. This increase was due to the small proportion of the parasite biomass in relation to the host biomass assumed in the model. It should be remembered, however, that parasites can compose a substantial portion of the biomass within an assemblage of hosts (Marcogliese \& Cone 1997, review). Thus, if more robust mass balance models are constructed, including more than just a small portion of the parasites in the web, the flux system may increase in a representative way.

Application of the Ecoranger routine produced a very tight interval in parasite biomass oscillation. When parasites were made to prey in all the heterotrophic compartments, larger biomass contributions than those obtained with Ecoranger were produced, making it impossible to balance the model. The model did support large parasite biomass values when these preyed only on benthos, indicating a high capacity for the benthos compartment to support high parasite biomass values. Introduction of parasites into compartments at the top of the trophic chain (i.e. fish) produced notable chain reactions in the entire system of compartments. This is obvious in a certain form because fish have wide spectrums of influence on trophic structure, meaning that any change in them can produce drastic chain reactions in the trophic network. Of additional interest is that there should be important control elements of intermediate condition parasites that allow a low parasite incidence in the host terminals.

In an experiment in the Ythan estuary, Aberdeenshire, UK (Huxham et al. 1995), the inclusion of parasites in snails, fishes and birds increased the maximum and mean food chain lengths, increased the proportion of top species and of omnivory, and decreased the proportion of basal species. Despite the simplicity of the parasite system models in the present study, there were several properties similar to those mentioned above. An analogy can also be made with Huxham et al. (1995) in terms of the proportion of top and basal species when parasites were introduced into the Ythan estuary and into the present study models. When parasites were included in the respective models, trophic efficiency did not decline over succeeding trophic levels as it did when parasites were not included. This suggests that the basal trophic levels did not dominate the upper levels, as has been documented in comprehensive and planktonic coral reef food webs (AriasGonzález et al. 1997, Niquil et al. 1999). In other words, when parasites are included in the model, detritivory and herbivory do not dominate carnivory, which produces a better transfer efficiency into the upper trophic levels and a generally more efficient system. With the 


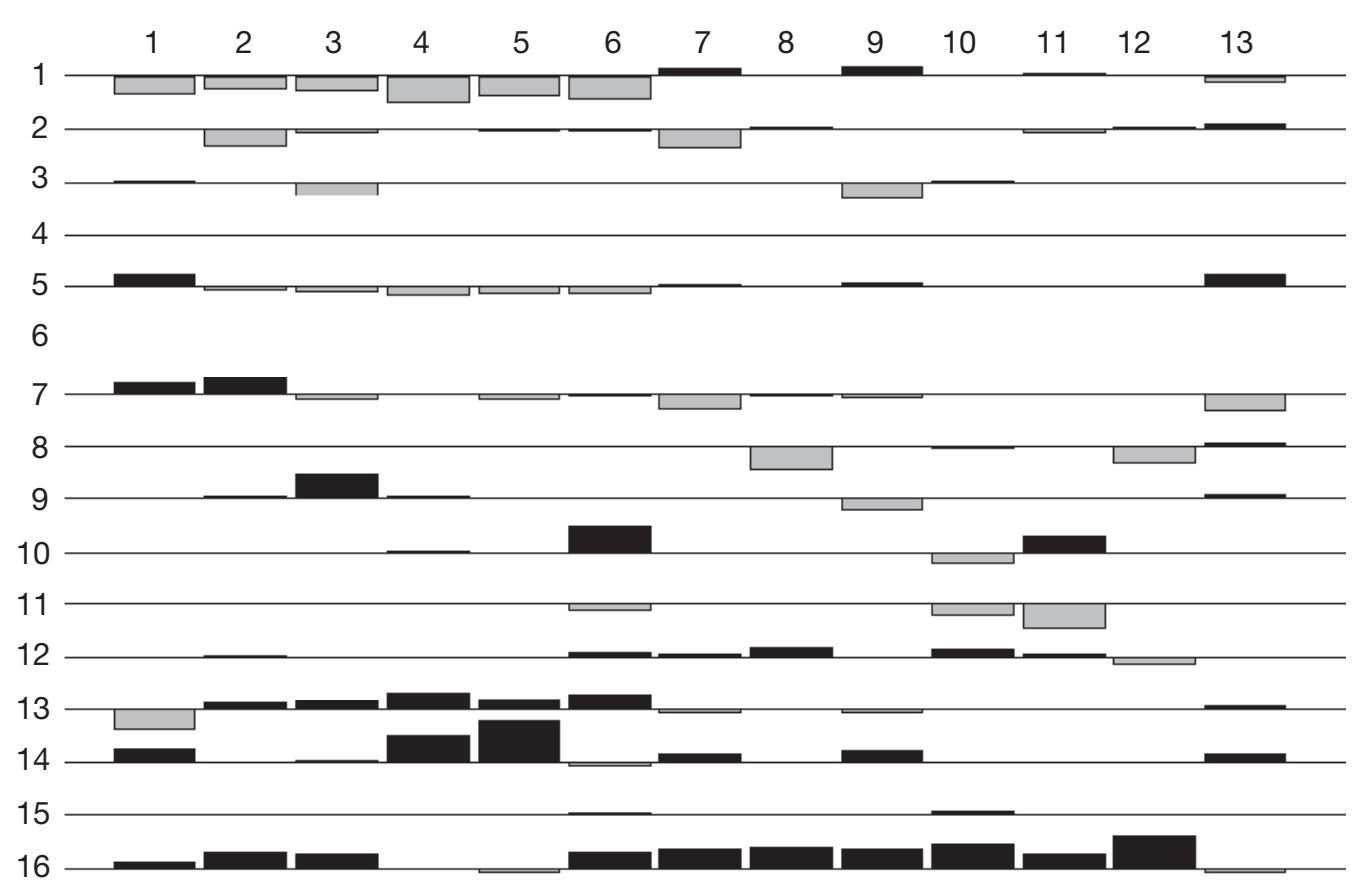

Fig. 2. Mixed trophic impacts of the model with parasites and microfauna, showing the effect of the increase in biomass of each trophic group on the other trophic group. Positive effects are shown above the lines (in black), negative effects below (in grey). See Fig. 1 for designations of trophic groups

exception of the benthos-parasite model with parasites, all the models with parasites have high transferences to the upper trophic levels. There was also a general extension of food chain length with the introduction of parasites. This is relevant because there has been much discussion of food chain length in ecosystems and of how different models show that non-introduction of parasites can produce misinterpretation of results. A conclusive aspect is that the trophic efficiencies and trophic chains are longer than previously thought, and longer than those that have been published in the literature. Thompson et al. (2005) obtained a very similar result: the inclusion of all parasite species in a food web resulted in greatly increased mean and maximum food chain lengths. Despite the fact that there is a clear consequence of adding parasites into the mass balance models as a 'super predatory/prey group', our results are consistent with studies derived from natural food webs, such as those of Huxham et al. (1995) and Thompson et al. (2005).

Something quite evident in this sense was the synergistic effect of parasites on ecotrophic efficiency and trophic chain length. These 2 macro-indicators increased considerably, suggesting a relevant aspect: that long food chains could be good indicators. Recently, different models of fisheries impact on reef ecosystems suggest that fisheries impact increases ecosystem trophic efficiency and food chain length (Arias-González et al. 2004). Within an in situ experi- ment, the aforementioned authors found shorter trophic chains and lower trophic efficiencies in systems protected against fisheries.

Pimm (1982) suggested that energy flow could not be the sole factor limiting food chain length. Pimm considered prey size and optimal foraging to be determining factors of food web length. Arias-González et al. (1997) have already stated that food web length is not only determined by the rate of primary production, but also by system trophic dynamics. The present results confirm the results of both these publications. The addition of an element that interacts at different trophic levels, in this case parasites, produces an increase in food web length and trophic efficiency. This makes these 2 trophic structure attributes potential system indicators, though it still needs to be determined at what extension of the trophic structure of trophic efficiency it can be said that systems are stressed or not. What can be generalised according to ecological theory is that long trophic chains and trophic efficiencies $>10 \%$ could indicate significant stress upon individual organisms.

The mixed results analysis shows interesting and variable results, in that the introduction of parasites in benthos and in the same parasites does not strongly impact indirect system interaction. It does, however, impact specific compartments, directly in the case of macrofauna and indirectly in carnivorous fish and, slightly less so, in piscivorous fish. Introduction of parasites in fish and parasites considerably impacted car- 
nivorous fish, with a consequent positive impact in the other fish compartments.

Attributes related to matter recycling and global attributes were generally insufficiently sensitive to show a change between systems with and without parasites. These attributes are highly related to matter and energy flow in the systems, and, thus, the low biomass addition represented by parasites was not enough to change the overall structure of the system.

The introduction of microfauna changed the relative responses of models with versus without parasites. It was observed that the model with microfauna was less sensitive to changes in system trophic structure. Many ECOPATH models currently assimilate microfauna (i.e. bacteria) with detritus, to produce greater sensibility in results. This omission, however, can lead to erroneous conclusions in system matter and energy flows. Recently, the importance of a type of bacteria (photosynthetically competent anoxygenic phototrophic bacteria), a hitherto unrecognised component of the marine microbial community, appeared to be critical to the cycling of both organic and inorganic carbon in the ocean (Kolbert et al. 2001).

Morand \& Arias-González (1997) have stressed the need to take parasites into account in dynamic model ecosystems. These authors emphasised that parasitism cannot be thought of simply as a form of prey-predator relationship, and they demonstrated that the effects of parasitism depend on lifestyle (simple vs. complex) and on the manipulative effect of parasites on their hosts. In the simple model used in the present study, parasites acted in a simple prey-predator relationship, because they were made to interact directly with the heterotrophic compartments. Lifestyle was not taken into account to aggregate them into a trophic guild, and whether they have monospecific or multispecific relationships in the systems was not considered. Nonetheless, despite the simplicity of the model, similar responses were observed in the behaviour of the model system with parasites and that observed in in situ experiments (e.g. Huxham et al. 1995) and in other food web models taking parasites into account (Thompson et al. 2005).

We already know that parasitism is a cryptic, but missing, element in model ecosystems (Morand \& Arias-González 1997). The present study confirms this by demonstrating that parasitism is a cryptic and missing element in mass balance and network analysis ecosystems. Even though incorporating parasites into the analysis, as done in this study, does not change system flows in a quantitatively important way, it does change the trophic structure in a very important qualitative way, producing considerable increases in the pathways, trophic levels and trophic efficiency of the system. Consequently, omission of parasites in mass balance and network models may lead to high inaccuracies in web patterns (i.e. pathways, cycles) and trophic structure (i.e. chain length, trophic efficiency).

Acknowledgements. We thank Dr. R. Ulanowicz, Dr. V. Christensen and 3 reviewers for their helpful comments on this manuscript.

\section{LITERATURE CITED}

Arias-González JE (1993) Fonctionnement trophique d'un écosystème récifal: secteur de Tiahura, île de Moorea, Polynésie française. Thèse de doctorat, EPHE, Perpignan

Arias-González JE, Delesalle B, Salvat B, Galzin R (1997) Trophic functioning of the Tiahura reef sector, Moorea Island, French Polynesia. Coral Reefs 16:231-246

Arias-González JE, González-Salas CF, Nuñez-Lara E, Galzin R (2004) Trophic models for investigation of fishing effect on coral reef ecosystems. Ecol Model 172:197-212

Baird D, Ulanowicz RE (1989) The seasonal dynamics of the Chesapeake Bay ecosystem. Ecol Monogr 59(4):329-364

Baird D, Ulanowicz RE (1993) Comparative study of the trophic structure, cycling and ecosystems properties of four tidal estuaries. Mar Ecol Prog Ser 99:221-237

Baird D, McGlade JM, Ulanovicz RE (1991) The comparative ecology of six marine ecosystems. Phil Trans R Soc Lond B 333:15-29

Christensen V, Pauly D (1992) ECOPATH II-a software for balancing steady-state ecosystems models and calculating network characteristics. Ecol Model 61:169-185

Christensen V, Pauly D (eds) (1993) Trophic models of aquatic ecosystems. Conf. Proc. 26, ICLARM, Manila

Christensen V, Pauly D (1998) Changes in models of aquatic ecosystems approaching carrying capacity. Ecol Appl (Suppl) 8:S104-S109

Christensen V, Walters CJ, Pauly D (2002) Ecopath with Ecosim Version 5. University of British Columbia, Fisheries Centre, Vancouver. Available at www.ecopath.org

Finn TJ (1976) Measures of ecosystem structure and function derived from the analysis of flows. J Theor Biol 56: 363-380

Freeland WJ, Boulton WJ (1992) Coevolution of food webs: parasites, predators and plant secundary compounds. Biotropica 24:309-327

Huxham M, Raffaelli D, Pike A (1995) Parasites and food web patterns. J Anim Ecol 64:168-176

Huxham M, Beaney S, Raffaelli D (1996) Do parasites reduce the chances of triangulation in a real food web? Oikos 76 : 284-300

Kay JJ, Graham LA, Ulanowicz RE (1989) A detailed guide to network analysis. In: Wulff F, Field JG, Mann KH (eds) Network analysis in marine ecology: methods and applications. Springer-Verlag, Heidelberg, p 15-61

Kolbert ZS, Plumley FG, Lang AS, Beatty JT and 6 others (2001) Contribution of aerobic photoheterotrophic bacteria to the carbon cycle in the ocean. Science 292: 2492-2495

Lawton JH, Warren PH (1988) Static and dynamic explanations for patterns in food webs. Trends Ecol Evol 3: $242-245$

Marcogliese DJ (2001) Pursuing parasites up the food chain: implications of food web structure and function on parasite communities in aquatic systems. Acta Parasitol 46:82-93

Marcogliese DJ (2002) Food webs and the transmission of parasites to marine fish. Parasitology (Suppl) 124:83-99 
Marcogliese DJ, Cone DK (1997) Food webs: a plea for parasites. Trends Ecol Evol 12:320-325

Monaco ME, Ulanowicz RE (1997) Comparative ecosystem trophic structure of three U.S. mid-Atlantic estuaries. Mar Ecol Prog Ser 161:239-254

Morand S, Arias-González JE (1997) Is parasitism a missing ingredient in model ecoystems? Ecol Model 95:61-74

Niquil N, Arias-González JE, Delesalle B, Ulanowicz R (1999) Characterization of the planktonic food web of Takapoto atoll, using network analysis. Oecologia 118:232-241

Parker GA, Chubb JC, Ball MA, Roberts GN (2003) Evolution of complex life cycles in helminth parasites. Nature 425: $480-484$

Pimm SL (1982) Food webs. Chapman \& Hall, London

Polis GA (1991) Complex trophic interactions in deserts: an empirical critique of food-web thEOry. Am Nat 138: 123-155

Polovina JJ (1984) Model of a coral reef ecosystems I. The ECOPATH model and its application to French Frigate Shoal. Coral Reefs 3:1-11

Polovina JJ (1985) An approach to estimating an ecosystem box model. US Fish Bull 83:457-460

Polovina JJ, Ow MD (1983) ECOPATH: a user's manual and program linstings. Nat Mar Fish Serv, NOAA, Honolulu Admin Rep H-83-23

Poulin R, Morand S (2000) The diversity of parasites. Q Rev Biol 75:277-293

Poulin R, Morand S (2004) The parasite biodiversity. Smithsonian Institution Press, Washington, DC

Rigby MC, Lo CM, Cribb TH, Euzet L, Faliex E, Galzin R, Holmes JC, Morand S (1999) The parasites of coral reef fishes of French Polynesia: checklist and preliminary findings. Cybium 23: 273-284

Skorping A, Högstedt G (2001) Trophic cascades: A role for parasites? Oikos 94:191-192

Editorial responsibility: Kenneth $R$. Tenore (Contributing Editor), Solomons, Missouri, USA
Sukhdeo MVK, Hernandez AD (2005) Food web patterns and the parasite's perspective. In: Thomas F, Guegan JF, Renaud F (eds) Parasitism and ecosystems. Oxford University Press, Oxford, p 54-67

Thomas JF, Guegan F, Renaud F (2004) Parasitism and ecosystems. Oxford University Press, Oxford

Thompson RM, Mouristen K, Poulin R (2005) Importance of parasites and their life cycle characteristics in determining the structure of a large marine food web. J Anim Ecol 74: $77-85$

Ulanowicz RE (1986) Growth and development: ecosystem phenomenology. Springer Verlag, Berlin

Ulanowicz RE (1997) Ecology, the ascendent perspective. In: Allen TFH, Roberts DW (eds) Complexity in ecological systems. Columbia University Press, New York

Ulanowicz RE (1998) A phenomenology of evolving networks. Syst Res Behav Sci 15:373-383

Ulanowicz RE (1999) NETWRK 4.2a: a package of computer algorithms to analyze ecological flow networks. Available at www.cbl.cees.edu/ ulan/ntwk/netwrk.txt

Ulanowicz RE, Norden JS (1990) Symmetrical overhead in flow networks. Int J Syst Sci 21(2):429-437

Ulanowicz RE, Puccia CJ (1990) Mixed trophic impacts in ecosystems. Coenoses 5:7-16

Walters C, Christensen V, Pauly D (1997) Structuring dynamics models of exploited ecosystems from trophic massbalance assessments. Rev Fish Biol 7:139-172

Wulff F, Ulanowicz RE (1991) A comparative anatomy of the Baltic Sea and Chesapeake Bay ecosystems. In: Wulff F, Field JG, Mann KH (eds) Network analysis in marine ecology: methods and applications. Springer-Verlag, Heidelberg, p 232-258

Wulff F, Field JG, Mann KH (eds) (1991) Network analysis in marine ecology: methods and applications. SpringerVerlag, Heidelberg

Submitted: September 30, 2005; Accepted: January 13, 2006 Proofs received from author(s): August 2, 2006 